\title{
Structural Characterizations for Glass Ionomer Cement Doped with Transition Metal Phthalocyanines
}

\author{
Gomaa El Damrawi ${ }^{*}$, Amal Behairy², Riham Atef ${ }^{3}$ \\ ${ }^{1}$ Physics Department, Faculty of Science, Mansoura University, Mansoura, Egypt \\ ${ }^{2}$ Basic Science Department, The High Institute of Engineering and Technology, New Damietta, Egypt \\ ${ }^{3}$ Chemical Engineering Department, The High Institute of Engineering and Technology, New Damietta, Egypt \\ Email: *gomaaeledamrawi@gmail.com
}

How to cite this paper: El Damrawi, G., Behairy, A. and Atef, R. (2019) Structural Characterizations for Glass Ionomer Cement Doped with Transition Metal Phthalocyanines. New Journal of Glass and Ceramics, 9, 67-79.

https://doi.org/10.4236/njgc.2019.94006

Received: July 4, 2019

Accepted: September 15, 2019

Published: September 18, 2019

Copyright $\odot 2019$ by author(s) and Scientific Research Publishing Inc. This work is licensed under the Creative Commons Attribution International License (CC BY 4.0).

http://creativecommons.org/licenses/by/4.0/

\begin{abstract}
Glass and Glass iomomer cement (GICs) based on a specific composition of cerium phosphate glass $\left(40 \mathrm{CeO}_{2}-60 \mathrm{P}_{2} \mathrm{O}_{5}\right)$ have been prepared. Effect of the doping type at a fixed doping concentration from metal-phthalocyanines (M-PCs) on material structure and morphologies has been carefully studied. The corresponding changes in the material structure were widely followed up by ${ }^{31} \mathrm{P}$ MAS NMR, X-Ray diffraction and FTIR spectroscopy. The network structure of both base glass and GIC which all free from metal phthalocyanines has been confirmed to be amorphous. GIC doped with M-PCs has shown a more ordered structure. There were clear changes in the position and intensities of ${ }^{31} \mathrm{P}$ NMR spectral peaks of glasses upon changing the dopant type. In all cases, a little concentration from M-Phthalocyanine (0.8 mol\%) leads to changing the network structure from amorphous to a more ordered structure. Phosphate structural phases are evidenced to be formed upon addition of a fixed amount of M-PCs ( $\mathrm{Ga}, \mathrm{Co}, \mathrm{Fe})$. The morphologies of some selected samples were characterized by SEM. The micrographs have revealed that formulating of cerium phosphate powder of the amorphous glass with a polymeric acid successfully led to the formation of $\mathrm{CePO}_{4}-\mathrm{H}_{2} \mathrm{O}$ bundles phases. But formulation with GIC containing Co or Fe or Ga Phthalocyanine can simply form co-aligned linear slaps and elongated nanofibers which are consisted of hydrated and carbonated $\mathrm{CePO}_{4}$ a $\mathrm{GaPO}_{4}, \mathrm{FePO}_{4}$ or $\mathrm{CoPO}_{4}$ crystals. The structure of all doped materials has a lower crack length than that of base glass. This was discussed on bases of formation of more aligned and elongated tough-fibers in matrix of all doped materials. Such tough fibers have ability to withstand breaking stress via suppressing crack propagation.
\end{abstract}

\section{Keywords}

Cerium Phosphate, Metal Phthalocyanine, Bundles Phases, ${ }^{31} \mathrm{P}$ NMR Spectroscopy 


\section{Introduction}

Some of Phthalocyanine (PCs) derivatives have been considered among the most important functional materials in many fields of applications [1]-[7]. PCs are characterized with their molecular structure which offers specific properties required for various technical and academic applications. PCs can be used as pigments in paints, data storage, IR security devices, printing inks, and computer disk writing [3] [4] [5] [6] [7]. In addition, PCs are known to have some specific medical application [8] [9]. They can be applied in photodynamic therapy of cancer [8] [9] [10]. They have several useful characteristics which have been related to their efficient ability for the electron transfer process [6] [7] [8] [9]. The central cavity of phthalocyanines is simply capable for accommodation of different elemental ions, including hydrogen and metal cations. A phthalocyanine containing one or two metal ions is called a metal phthalocyanine (M-PC). The high electron transfer abilities of M-PC have recommended them to be utilized in many fields such as molecular electronics, optoelectronics, photonics, etc. [2]-[7]. The behaviors of M-PCs are almost based on electron transfer reactions which originate from the $18 \pi$ electron conjugated ring system found in their molecular structure.

The strongest absorption of M-PC in the visible region can be attributed to the electron transition from the allowed highest occupied molecular orbital to the lowest unoccupied molecular orbital which is called $\left(\pi-\pi^{*}\right)$ transition. For many applications the maximum absorption of M-PC has to move toward near the infrared region. In such a case, M-PC will be formulated with some types of organic solvent to yield a high strain structure. There are further additional particular derivatives which are known to have specific potential applications as second-generation photosensitisers for photodynamic therapy (PDT) of cancer [8] [9] [10]. These materials have shown a strong absorption of the far-red light between the wavelengths of 600 and $850 \mathrm{~nm}$, which has greater tissue penetration properties. Phosphate glasses which were modified by metal oxides, fluoride and Phthalocyanine $\left(\mathrm{CeO}_{2}, \mathrm{Ag}_{2} \mathrm{O}, \mathrm{CrF}_{2}, \mathrm{C}_{32} \mathrm{H}_{16} \mathrm{ClGaN}_{8}\right)$ [11] [12] [13] [14] have increasing scientific interests. This may be due to their appropriate state which is closely connected with application in biology, materials science and engineering [1]-[9].

The structure of vitreous $\mathrm{P}_{2} \mathrm{O}_{5}$ consists of tetrahedral groups represented by $\mathrm{Q}^{\mathrm{n}}$ notations ( $\mathrm{Q}$ is phosphors cation, $\mathrm{n}$ is the number of bridging oxygen atoms). A gradual increasing of a modifier oxide in $\mathrm{P}_{2} \mathrm{O}_{5}$ network could result in transforming $\left(\mathrm{Q}^{3}\right)$ to another phosphate units of more non bridging oxygen (NBO) ions $\left(\mathrm{Q}^{2}, \mathrm{Q}^{1}\right.$ and $\left.\mathrm{Q}^{0}\right)$ [11] [12] [13]. As a result, the well-formed chains of $\mathrm{P}_{2} \mathrm{O}_{5}$ become shorter and transformed into isolated rings like structure through increasing NBO atoms. In the glasses enriched with NBO atoms, separated rings containing only two identical molecules called dimers species can be formed. The latter species are the most formed structural configuration in phosphate glass which is considered as an essential counterpart in obtaining the desired 
type of glass ionomer cement (GIC).

In terms of bioengineering applications, GICs is considered as an important type which can be prepared by mixing the fine powder of the glass sample with soluble type of weak acids. As a result of base-acid interaction between the glass powder and the poly acid, GIC can be simply formed [14] [15] [16] [17]. Specifically, GICs based on phosphate glasses are the most useful type. This may because $\mathrm{P}_{2} \mathrm{O}_{5}$ based glasses are characterized with their higher basic reaction than that of germinate, telluride, silicate and borate glasses. For this reason, the characteristic of glass ionomer cements might be dominantly based on reaction between polymeric acid and the powder of phosphate glass.

Some important types of additional row materials such as metals or rare earth oxides or fluorides have to be added to the base GIC, since they can play the role of enhancing both bioactivity and compatibility of the used materials. Some of specific dopants can be added to stimulate the growth rates of the nucleation and crystallization processes of the mineral phase of bio hydroxyl phosphate structure [14] [15]. GICs involving crystalline phases can simply possess more enhanced properties than that non biocompatible amorphous GIC.

Majority of previous studies on GICs were concerned with effect of specific types of transition oxides on biocompatibility [11] [12] [13]. Whereas, modifications of GIC with a metallic Phthalocyanine species as an organic agent for nucleation, crystallization and as antimicrobial agents, are limited [14]. Therefore this study is devoted to explore the role played by different TM Phthalocyanines in modification of cerium phosphate based GIC to become appropriate in the field of tissue engendering applications. The main objective is to characterize both the structure and properties of the well-prepared glass ionomer cements. In addition, the structural role of M-PCs in achieving such properties can be determined.

\section{Experimental}

\subsection{Preparation}

Glasses of a chemical composition $400 \mathrm{CeO}_{2} \cdot 60 \mathrm{P}_{2} \mathrm{O}_{5}$ have been prepared using ordinary slowly cooling technique. Reagent grades (Aldrich company) $\mathrm{CeO}_{2}$ and $\mathrm{NH}_{4} \mathrm{H}_{2} \mathrm{PO}_{4}$ (purity 98.93, 99.89) are the raw materials used in glass preparation. The glasses were prepared by melting the mixtures in an aluminum crucible in an electric furnace at about $1250^{\circ} \mathrm{C}$. After solidification of the glass, it reheated in an electric furnace at tempering temperature of $300^{\circ} \mathrm{C}$ for 3 hours to release internal stresses.

\subsection{Measurements and Techniques}

XRD diffraction measurements were carried out on a Brucker Axs-D8 spectrometer. Emitting source of type $(\lambda \mathrm{CuK} \alpha)$ has been utilized. The numerical data were frequently accumulated with a small scanning step, $2 \theta$ rang of $5^{\circ}-70^{\circ}$ and a dwell time of 0.4 seconds have been applied. The obtained X-ray diffraction spectra were revised to reference samples related to standards which were ga- 
thered by the technique of powder diffraction and standards (JCDPS). The surface structure of the investigated samples was characterized using JEOL JSM-6510 LV electron microscope operated at accelerating voltage $30 \mathrm{KV}$, with a magnification $10 \times$ up to $400.000 \times$. For the SEM study, the samples were coated with gold to prevent scattering of the electron beam. The FTIR absorption spectra were recorded using the $\mathrm{KBr}$ pellet technique. A Mattson 5000 FTIR spectrometer, with a $2 \mathrm{~cm}^{-1}$ resolution, was used to obtain the spectra in the range $400-4000 \mathrm{~cm}^{-1}$ at room temperature. In average 20 scans are accumulated to form the spectrum of each sample. ${ }^{31} \mathrm{P}$ NMR spectra of powdered samples were recorded with a spectrometer operating at 11.74T (Joel -500, Mansoura University). Pulses with $10 \mathrm{~s}$ delay time were used and about 500 scans are obtained.

\section{Results and Discussion}

\subsection{Appearance Properties}

Phosphate GICs containing metal-Phthalocyanines (M-PCs) have been previously studied in terms of changing M-PCs concentrations [14] [18] [19] [20]. In the present research, we enlarge the range of study by fixing the doping level and change the dopant type. The structure and some properties of three different types of metallic ( $\mathrm{Ga}, \mathrm{Co}, \mathrm{Fe})$ Phthalocyanines have been studied in the present work.

Figure 1 reflects the effect of changing the doping type on the visual or appearance of GICs. As presented in Figure 1, cerium phosphate glass of P/Ce molar ratio $=1.5$ (Figure $1(\mathrm{a})$ ) has the yellowish color. GICs of $0.8 \mathrm{Ga}$, Co and Fe-Phthalocyanines have a dark blue, dark violet and black color, Figures 1(b)-(d), respectively. The change of the color is considered due not only to changing the valence state of the metallic cation but also due to changing its coordination number in the corresponding matrix of GIC [14].

As shown from Figures 1(a)-(d) there is a clear difference among the color of GICs containing different types of transition metal complexes. The change of color in the investigated GIC may be raised from electronic transitions between levels whose spacing corresponds to the wavelengths available in the visible light [1] [17]. These transitions are frequently referred to as $d-d$ transitions because they involve the orbitals that are mainly $d$ in character. Specifically, the exhibited colors are intimately related to the magnitude of the spacing between the energy levels which depend on the geometry of the complex, the nature of the ligands,

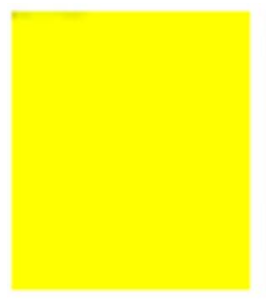

(a)

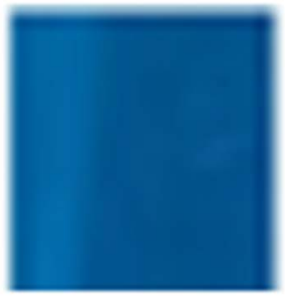

(b)

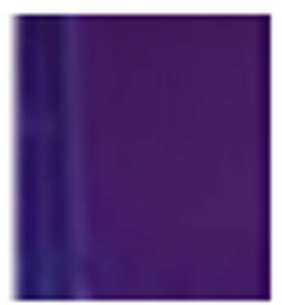

(c)

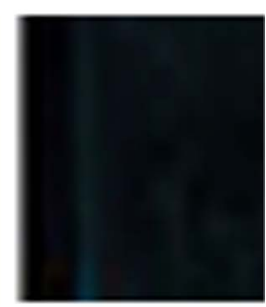

(d)

Figure 1. (a) Color of as obtained glass, (b), (C) and (d) appearance of GIC containing $\mathrm{Ga}$, Co and Fe PCs. 
and the oxidation state of the central metal atom. In some cases the origin of the color is not only due to the d-d transitions, but also it may be due to charge transfer between central atom and the ligand (such as molecules which coordinated to central atoms, $\mathrm{O}, \mathrm{PO}_{4}$ groups and etc.). Similar to d-d transitions, charge-transfer (CT) transitions also involve the metal d-orbitals. Legend to metal charge transfer from $\mathrm{O}^{2-}$ to $\mathrm{Ga}$, Co ((VII), Ce, Fe), described as LMCT band is simply accessible to occur in the investigated materials. In this case the charge transfer occurs from Fe(II) to the empty $\pi^{\star}$ orbital of legend. Then charge transfers absorptions can be also considered due to movement of electrons between metal and ligand. This process is often 1000 times stronger than $\mathrm{d}-\mathrm{d}$ transition bands [1] [14] [16] [17].

\section{2. ${ }^{31}$ P NMR Spectroscopy}

As can be observed in Figure 2, it is interesting to compare the peak position (chemical shift values) of the NMR spectra of the investigated materials containing $\mathrm{Ga}, \mathrm{Co}$, and Fe Phthalocyanine (spectral c, d, and e) with that of metal free sample $(a, b)$. As would be expected, the full width at half maximum (FWHM) and the spectral area of M-PC free samples (a, base glass, b base GIC) is much higher than that of samples containing M-PC (c, d and e).

The spectra of the free metal glass contain two resonance peaks at different values of chemical shifts $(-27.5$ and $-33 \mathrm{ppm})$. On the other hand, spectra of samples containing $\mathrm{Ga}$, Co and $\mathrm{Fe}-\mathrm{PCs}$ have shown symmetric spectra with one specific value of chemical shift $(-33 \mathrm{ppm})$ for $\mathrm{Ga}$ and Co and $-35 \mathrm{ppm}$ for Fe-PC. This may reflect the change of the bond character on the phosphors central

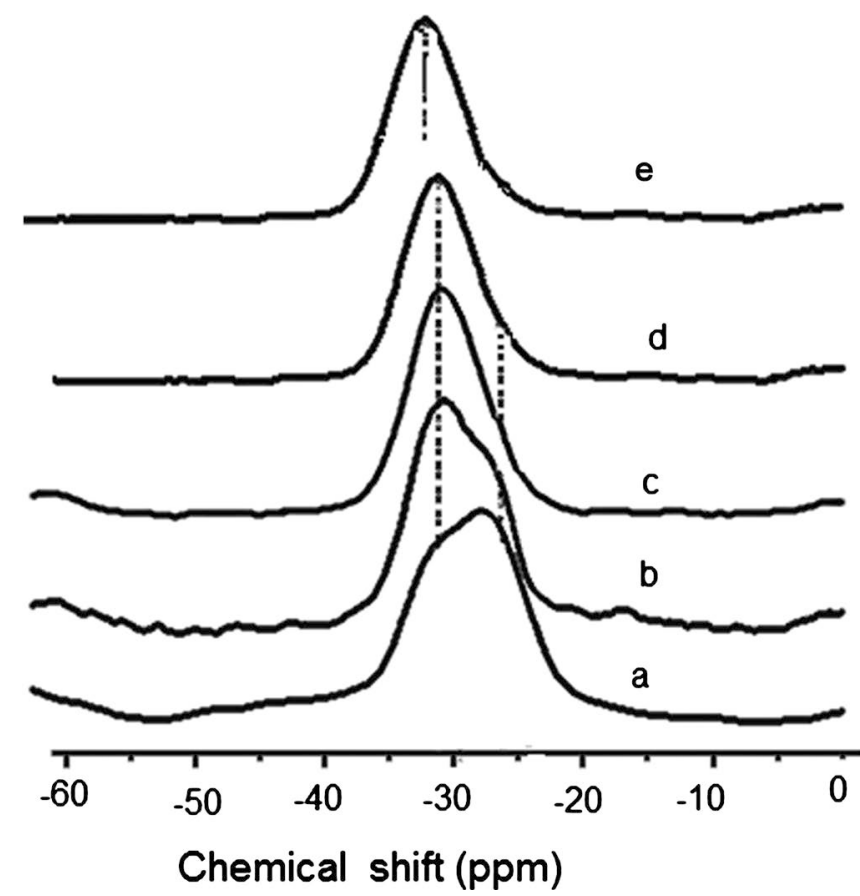

Figure 2. The ${ }^{31} \mathrm{P}$ MAS-NMR spectra (a) Base glass, (b) GIC, (c, d, e) GIC containing a fixed concentration ( $0.8 \mathrm{~mol} \%$ ) from $\mathrm{Ga}, \mathrm{Co}, \mathrm{Fe}$ Phthalocyanines 
atoms [19] [20] [21]. These differences are attributed to the presence of the more electronegative metal ions bonded through the $\mathrm{NBO}$ in the $\mathrm{PO}_{4}$ units. From the feature of the spectra ( $a$ and $b$ ), the ${ }^{31}$ PNMR studies suggest an increase in the magnitude of non-bridged oxygen atoms (NBO) around the phosphate atoms. But in samples containing M-PSC ( $c, d, e)$, there is an increasing of the group types bonded to NBO atoms in the phosphorus. This consideration is based on the large change between NMR spectra of a metal free and the metal containing samples which are evidenced from Figure 2. As can be seen from spectra (c, d, e), one symmetric resonance peak at the same value of chemical shift ( $-33 \mathrm{ppm})$ is only recorded for samples containing Ga and Co-PCs and lower value of -35 ppm is recorded for Fe-PC. On comparison to M-PSc free materials, spectra of duple resonance are presented $(\mathrm{a}, \mathrm{b})$.

Generally, NMR spectra of the as prepared $40 \mathrm{CeO}_{2}-60 \mathrm{P}_{2} \mathrm{O}_{5}$ glass have showed two broad peaks around -27.5 and $-33 \mathrm{ppm}$ assigned to mixtures from both meta and pyrophosphate environments. The ${ }^{31} \mathrm{P}$ MAS-NMR spectra of the Ga, Co and Fe Phthalocyanine (c, d, e) show a similar pattern of lines. A chemical shift values found around $-33 \mathrm{ppm}$ for $\mathrm{Ga}$ and $\mathrm{Co},(\mathrm{c}, \mathrm{d})$ and at $-35 \mathrm{ppm}$ for Fe-PSC (e) are the features of the obtained spectra.

The broad peak at $-27.5 \mathrm{ppm}$ in the original glasses is decreased and resonance peak at $-33 \mathrm{ppm}$ is resolved via addition of $0.8 \mathrm{~mol} \%$ metal Phthalocyanine. These changes lead to suggest that, addition of a fixed value of metallic ( $\mathrm{Ga}, \mathrm{Co}, \mathrm{Fe}$ ) Phthalocyanine affects significantly the phosphor environment in the glass structure. This suggests an additional mechanism that promotes the cross-linking reaction and therefore the setting of the cements. Generally, disappearing of resonance at $-27.5 \mathrm{ppm}$ and resolving of the resonance peak at -35 ppm as a result of addition of 0.8 metal Phthalocyanineis mainly due the forming of different bridging ligands in the second coordination spheres of $\mathrm{P}$ atoms [14]. Bridging of metals ligands with $\mathrm{PO}_{4}$ groups should result in an increase in the number of bridging bonds between the central metal and $\mathrm{PO}_{4}$ units which decrease the chemical shift of $\mathrm{P}$ muclei due to forming of the more shielded species. Specifically, the cements based on M-Phthalocyanine show different tendencies from that of free M-Phthalocyanine glasses. The negative chemical shifts are larger compared to the cement based on the metal. In addition, the peak intensity is increased and shifted toward more negative direction (spectra d). The change of the chemical shift is considered not only due to changing of the valence state of the metallic cation but also due to change of coordination number of phosphors atoms in the corresponding matrix of GIC.

\subsection{XRD Analysis}

$\mathrm{X}$-ray diffraction spectra of the as prepared glass sample are presented by Figure 3 (a). As can be seen from this figure, a broad band in the range of $25^{\circ}-40^{\circ}$ of diffraction angles has been simply appeared. The broadening of this band can confirm the disordered structure of the base glassy material. Figure 3(b) 


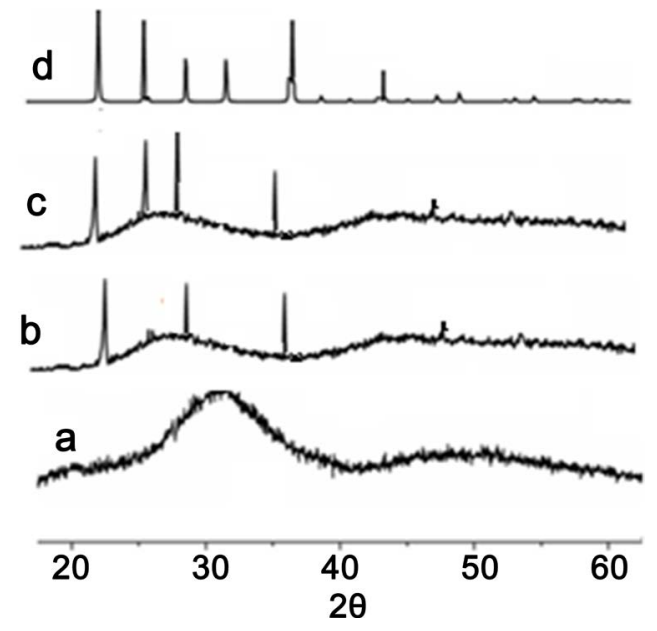

Figure 3. XRD spectra of base glass (a), glasses containing Ga, Co and Fe-PCs (b, c, d) respectively.

represents the spectra of the well prepared GIC containing $0.8 \mathrm{Ga}$. Three intense diffraction peaks which have been appeared at about $23^{\circ}, 28^{\circ}$ and $38^{\circ}$ are the main peak in the spectra. Structural analysis concerning the position of the both diffracted line spectra confirms a formation of metallic-phthalocyanine crystalline species of monoclinic structure [14] [22] [23] [24]. The Diffraction spectra presented by (c) (d) represent GICs of $0.8 \mathrm{~mol} \%$, Co and Fe-Phthalocyanine respectively. There are some sharp diffraction lines superimposed on the less broad diffraction patterns ( $\mathrm{c}$ and $\mathrm{d}$ ) in the GIC of $0.8 \mathrm{~mol} \% \mathrm{Ga}$ and Co and Fe-PSC. These spectra may represent two components of the well-formed structural configurations. One is due to the amorphous matrix (spectra a) and the other represent a crystalline matrix of the resined Ga and Co-PC (of spectra $\mathrm{b}$ and c). As a consequence, the spectra of glass of $0.8 \mathrm{~mol} \% \mathrm{Ga}$ and Co-PC contain a broad hump with a clear sharp diffraction peak. Much sharper diffraction peaks appear in sample of Fe-PSC (Figure 3(d)). In this case, the wide diffraction hump totally disappears confirming the presence of the highest crystalline phases, particularly in Fe-PSC GIC.

\subsection{FTIR Spectroscopy}

Figure 4 represents infrared spectra of oxide glass (a) and its GIC (b). It can be shown from Figure 4 and Figure 5 that there is an intensive absorbance at about $1800 \mathrm{~cm}^{-1}$ represents the acid-base reaction, since this peak may represent $\mathrm{C}-\mathrm{O}$ vibration in $\mathrm{PO}_{4}$ groups [14] [20]. This intense peak didn't appear in the spectra of the oxide glass, Figure 4(a). These changes may be considered due to the base-acid reaction which leads to degradation processes in material network [14] [20].

Increasing crystallization (as presented by XRD, Figure 3) is also evidenced from IR spectra of GIC containing distinguished types from metal-Phthalocyanine Figure 5. The one resolved peak at about $750 \mathrm{~cm}^{-1}$ in the spectra of both the glass and the GIC $(a, b)$ is transformed to envelop of splitting absorbance peaks 


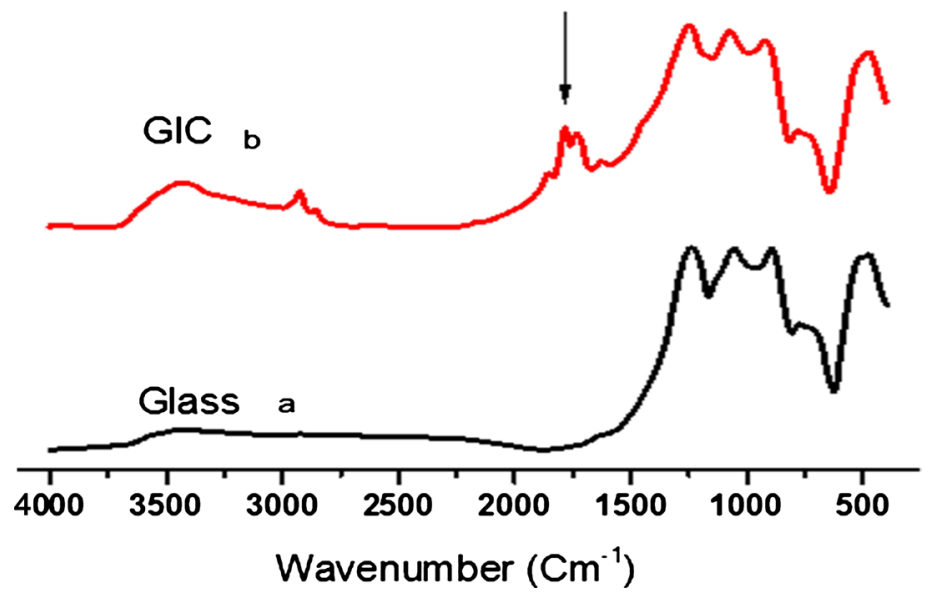

Figure 4. Experimental absorbance spectra (a) of as obtained as prepared sample and (b) of GIC.

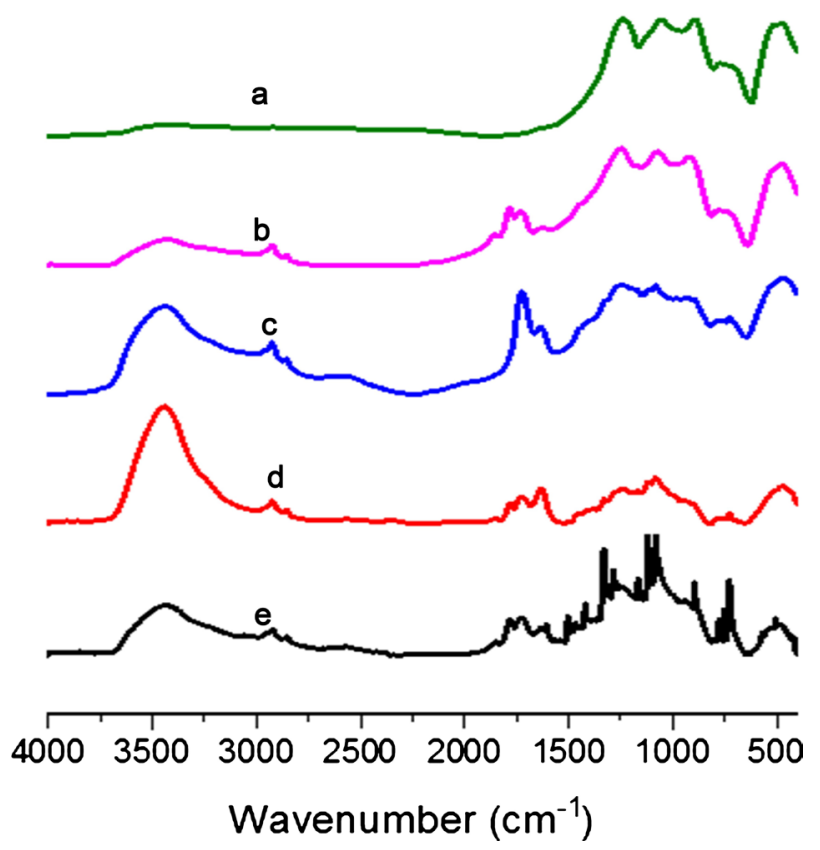

Figure 5. Curve (a) represent the as obtained glass and (b) represents the GIC, but (c, d, e) are the spectra of GIC contain Ga, Co and Fe-PCs.

around around $750 \mathrm{~cm}^{-1}$ and $1800 \mathrm{~cm}^{-1}$ in glasses containing $\mathrm{Ga}$, Co, and $\mathrm{Fe}$ (figure c, d, e). X-ray diffraction and IR-absorbance spectra of GIC containing Fe is shown to contain much sharper peaks which lead to higher crystallinity.

The absorbance at about $590 \mathrm{~cm}^{-1}$ can be related to the vibration of metallic ions $\mathrm{Ga}$ or $\mathrm{Ce},(\mathrm{Co}$ or $\mathrm{Fe})$ in crystalline phosphate species [14] [16] [20].

\subsection{Morphological Studies (SEM)}

The GIC could simply be prepared by the method of acid-base reaction [14] [16] [17] [18] [19] [20]. Presence of metal-Phthalocyanine (PCs) as an essential counterpart of the present investigated GIC is necessary to control the synthesis and achieve their application [14] since they can play a role of chelating or com- 
plexing additive.

The investigated morphology of the base glass is shown in Figure 6. It can observe that an extremely homogenous glass network is the dominant. On the other hand, formulating the glass powder with the acid successfully results in forming some types of structural species called pitted glass particles [14]. The latter has been embedded in a polysalt main glass matrix (Figure 7). But formulation

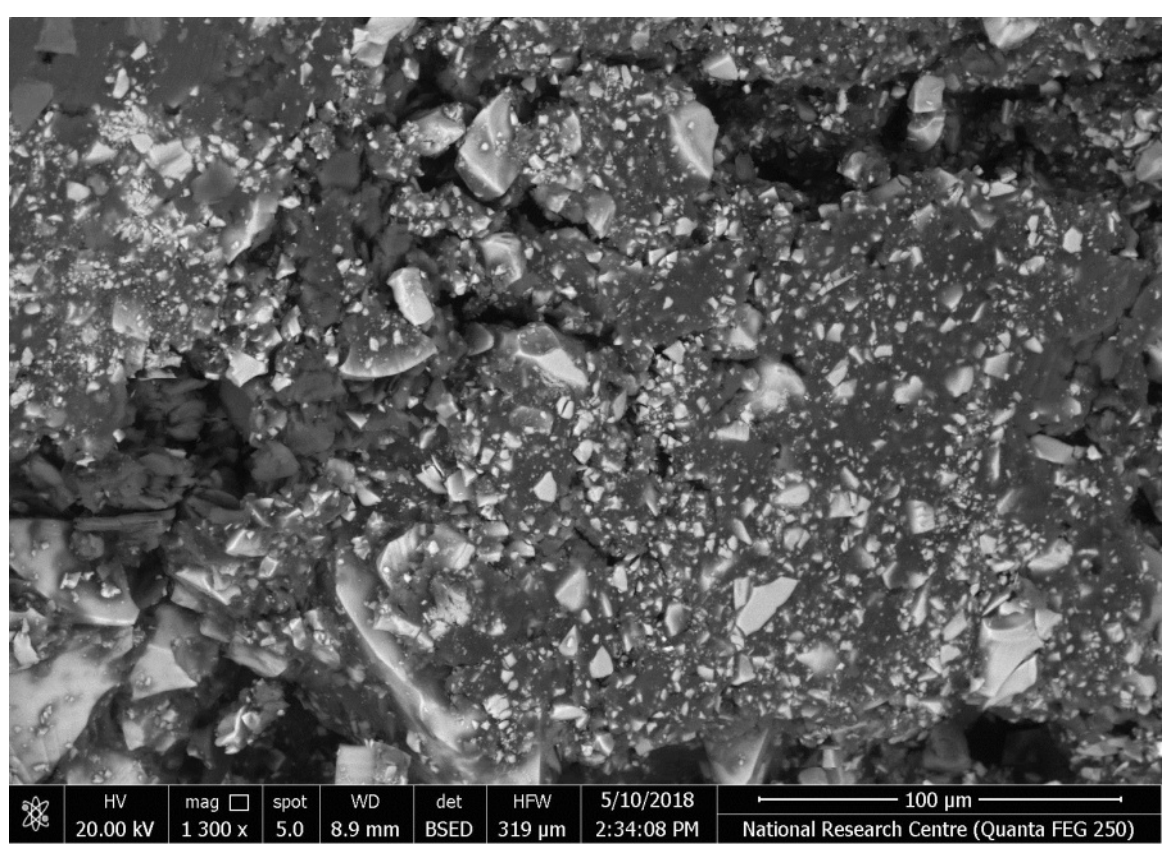

Figure 6. Micrograph of $\mathrm{CeO}_{2}-\mathrm{P}_{2} \mathrm{O}_{5}$ glass.

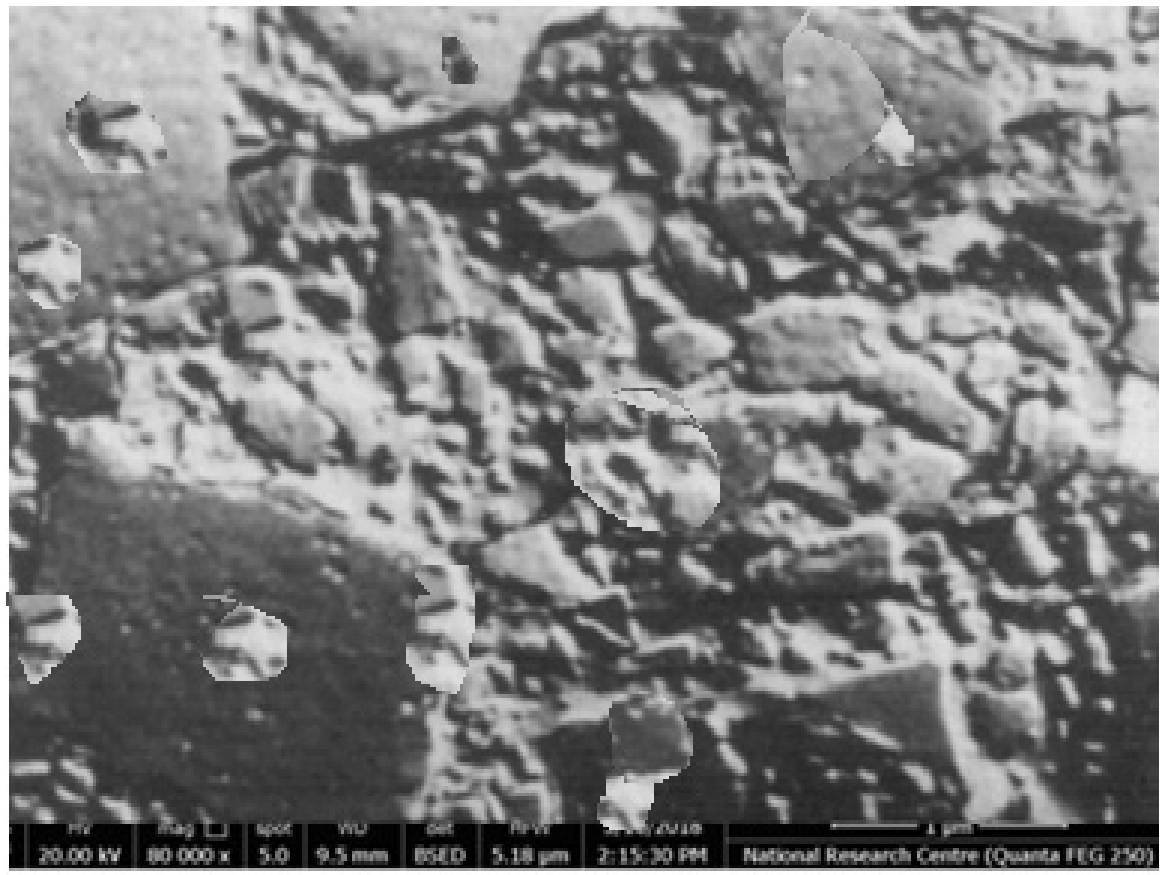

Figure 7. GIC (powder of cerium phosphate glass formulated with polymeric acid) showing pitted glass particles and embedded in a polysalt gel matrix. 
of GIC with Co-Phthalocyanine has formed a morphology containing bundles like species (Figure 8). The latter type is changed to more thinner, elongated and aligned rod-like species (Figure 9). The well-formed fibers are characterized with very lower thickness and much higher length, as shown in Figure 9. The well-formed nano fibers with more enhanced shapes may be recommended as important materials which have specific applications in tissue engineering

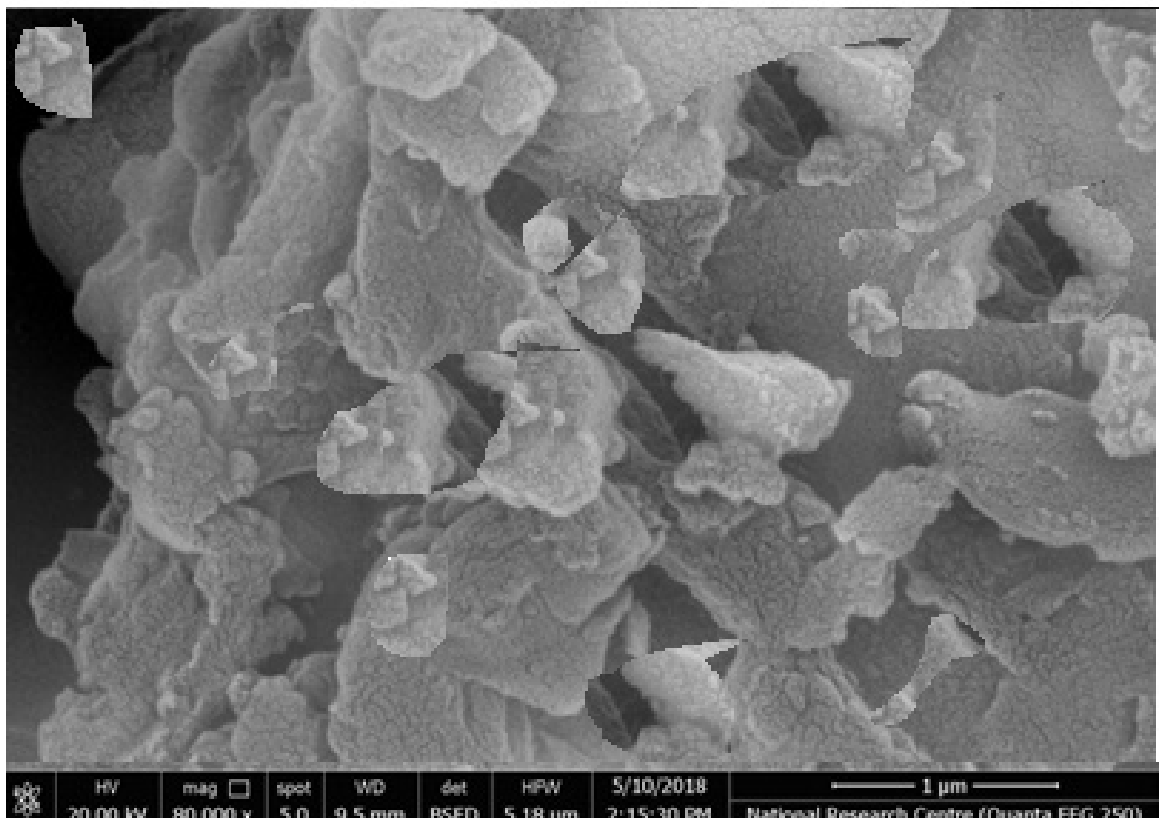

Figure 8. GIC containing $0.8 \mathrm{~mol} \%$ Co-Phthalocyanine, the morphology appears as bundles structure.

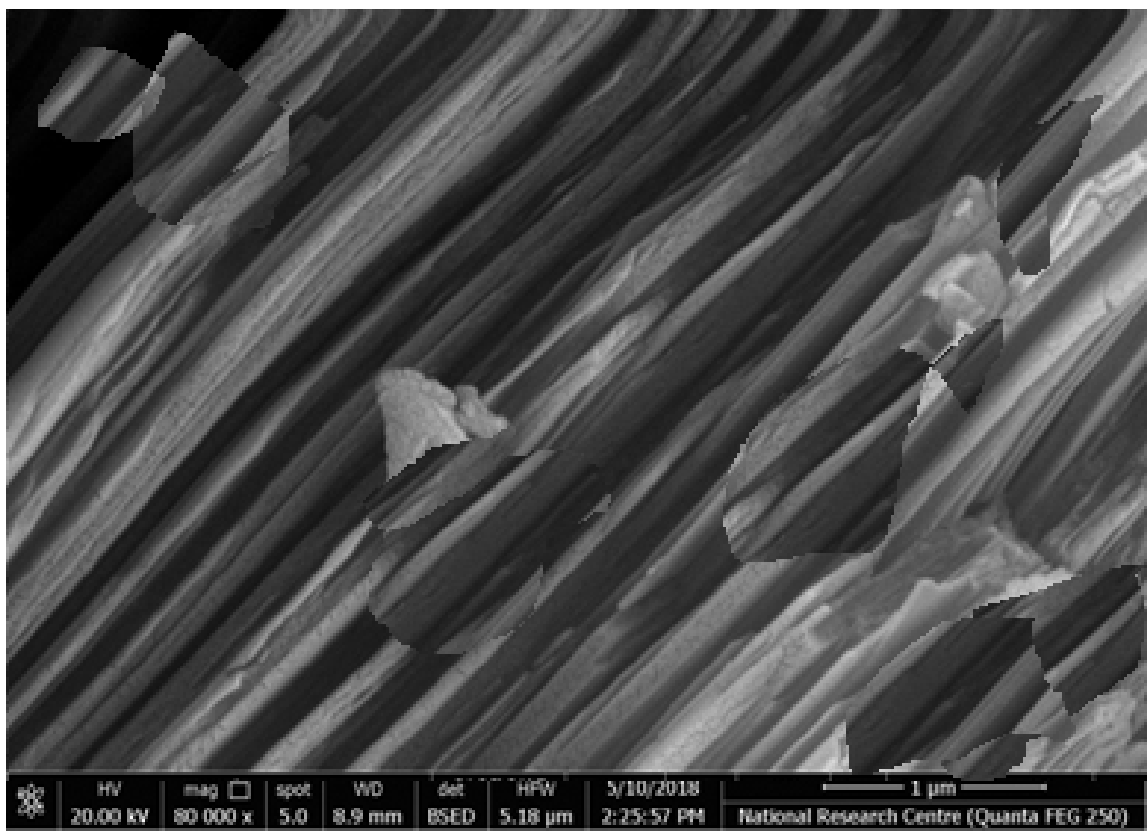

Figure 9. GIC containing. $8 \mathrm{~mol} \% \mathrm{Fe}$ Phthalocyanine, the morphology appears as elongated fibers or wafers like structure. 
or bio scaffolds. This may because the good affinity of carboxylate or peptide moieties for cerium phosphates pecies enhances the structure to simultaneously incorporate the precursor phosphate moieties which is called (grafting, Figure 9) throughout the self-assembled nano fibrous. The latter can be used as templates hybrid biomaterials [25] [26] [27] [28].

Finally, we recommend that the acid-base reaction applied to get GIC has to be performed under relatively specific circumstances ( $\mathrm{pH}$ around $4-4.5$ ) which may help in minimizing the strict characteristics of phosphates of reduced $\mathrm{pH}$ values $(<1.5)$. Such cases are considered to have importance to offer an elongated $\mathrm{CePO}_{4}$ fiber which can be reflected from SEM micrograp (Figure 9).

\section{Conclusion}

Cerium phosphate-based glasses ionomer cement containing small additives from M-PCs Phthalocyanines have been prepared and studied. XRD and SEM of base glass and base GIC have shown that the amorphous structure is the dominant. While formulating of GIC with M-PCs has adapted the morphology to contain crystalline fibers after cross-linking processes. Both bundle and rod-like shapes of crystals are found in M-PCs doped GIC. Morphology of bundle shapes is transformed to co-elongated fibered or wafers like shape in Fe-PCs sample. ${ }^{31} \mathrm{PNMR}$ results have confirmed that the phosphate structural units are highly shielded via bonds which were formed by the effect of M-PCs. This appeared from changing of chemical shift toward more negative value.

\section{Conflicts of Interest}

The authors declare no conflicts of interest regarding the publication of this paper.

\section{References}

[1] Hong, Z.R., Liang, C.J., Sun, X.Y. and Zeng, X.T. (2006) Characterization of Organic Photovoltaic Devices with Indium-Tin-Oxide Anode Treated by Plasma in Various Gases. Journal of Applied Physics, 100, Article ID: 093711.

[2] Park, Y.G., Kanki, T., Lee, H.Y., Tanaka, H. and Kawai, T. (2003) CuPc/PbZr ${ }_{0.2}$ $\mathrm{Ti}_{0.8} \mathrm{O}_{3} /(\mathrm{La}, \mathrm{Ba}) \mathrm{MnO}_{3}$ Field Effect Transistor Heterojunction Photomemory. SolidState Electronics, 47, 2221-2224.

[3] Heavens, O.S. (1991) Optical Properties of Thin Solid Films. Dover Publications, New York, 103.

[4] Karan, S., Basak, D. and Mallik, B. (2010) Persistence in Photoconductivity and Optical Property of Nanostructured Copper (II) Phthalocyanine Thin Films. Current Applied Physics, 10, 1117-1122.

[5] Heutz, S., Sullivan, P., Sanderson, B.M., Schultes, S.M. and Jones, T.S. (2007) Molecular Thin Films for Optoelectronic Applications. Solid State Phenomena, 121-123, 373-376. https://doi.org/10.4028/www.scientific.net/SSP.121-123.373

[6] Kılınç, N., Atilla, D., Gürek, A.G., Öztürka, Z.Z. and Ahsen, V. (2009) Tetrakis (Alkylthio)-Substituted Lutetium Bisphthalocyanines for Sensing $\mathrm{NO}_{2}$ and $\mathrm{O}_{3}$. Sensors and Actuators B: Chemical, 142, 73-81. 
https://doi.org/10.1016/j.snb.2009.07.015

[7] Armstrong, N.R. (2000) Phthalocyanines and Porphyrins as Materials. Journal of Porphyrins and Phthalocyanines, 4, 414-417. https://doi.org/10.1002/(SICI)1099-1409(200006/07)4:4<414::AID-JPP247>3.0.CO;2 $\underline{-\mathrm{B}}$

[8] Lim, C.K., Shin, J., Lee, Y.D., Kim, J., Oh, K.S., Yuk, S.H., Jeong, S.Y., Kwon, I.C. and Kim, S. (2012) Phthalocyanine-Aggregated Polymeric Nanoparticles as Tumor-Homing Near-Infrared Absorbers for Photothermal Therapy of Cancer. Theranostics, 2, 871-879. https://doi.org/10.7150/thno.4133

[9] Dolmans, D.E., Fukumura, D. and Jain, R.K. (2003) Photodynamic Therapy for Cancer. Nature Reviews Cancer, 3, 380-387. https://doi.org/10.1038/nrc1071

[10] Baptista, M.S. and Wainwright, M. (2011) Photodynamic Antimicrobial Chemotherapy (PACT) for the Treatment of Malaria, Leishmaniasis and Trypanosomiasis. Brazilian Journal of Medical and Biological Research, 44, 1-10. https://doi.org/10.1590/S0100-879X2010007500141

[11] Dutta, D.P. and Jai, V.K. (2000) Synthesis and Characterization of Phosphinic and Phosphate Complexes of Gallium(III) and Indium(III). Phosphorus, Sulfur, and Silicon and the Related Elements, 166, 15-26. https://doi.org/10.1080/10426500008076528

[12] Brow, R.K. (2000) Review: The Structure of Simple Phosphate Glasses. Journal of Non-Crystalline Solids, 263-264, 1-28. https://doi.org/10.1016/S0022-3093(99)00620-1

[13] El-Damrawi, G., Hassan, A., Doweidar, H. and Shaboub, A. (2017) Structural Studies on $\mathrm{Ag}_{2} \mathrm{O}-\mathrm{P}_{2} \mathrm{O}_{5}$ Glasses. New Journal of Glass and Ceramics, 7, 77-89. https://doi.org/10.4236/njgc.2017.73007

[14] El Damrawi, G., Behairy, A. and Abdelgany, A.M. (2018) Structural Characterization of Novel Cerium Phosphate Glass Ionomer Cements (GICs) Doped with GaCl (Phthalocyanine). New Journal of Glass and Ceramics, 8, 23-38. https://doi.org/10.4236/njgc.2018.82003

[15] Sidhu, S.K. and Nicholson, J.W. (2016) A Review of Glass-Ionomer Cements for Clinical Dentistry. Journal of Functional Biomaterials, 7, 16. https://doi.org/10.3390/jfb7030016

[16] Shahid, S., Hassan, U., Billington, R.W., Hill, R.G. and Anderson, P. (2014) Glass Ionomer Cements: Effect of Strontium Substitution on Esthetics, Radiopacity and Fluoride Release. Dental Materials, 30, 308-313.

[17] Engqvist, H., Schultz-Walz, J.E., et al. (2004) Chemical and Biological Integration of a Mouldable Bioactive Ceramic Material Capable of Forming Apatite in Vivo in Teeth. Biomaterials, 25, 2781-2787.

https://doi.org/10.1016/j.biomaterials.2003.09.053

[18] Liao, M.S. and Scheiner, S. (2001) Electronic Structure and Bonding in Metal Phthalocyanines, Metal $=\mathrm{Fe}, \mathrm{Co}, \mathrm{Ni}, \mathrm{Cu}, \mathrm{Zn}, \mathrm{Mg}$. The Journal of Chemical Physics, 114, 9780. https://doi.org/10.1063/1.1367374

[19] Ozaki, H. and Harada, Y. (1990) Penning Ionization Electron Spectroscopy of Iron Phthalocyanine Thin Films. Study of Electronic Structure from Local Electron Distribution of Molecular Orbitals. The Journal of Chemical Physics, 92, 3184. https://doi.org/10.1063/1.457915

[20] Orti, E. and Brédas, J.L. (1992) Photoelectron Spectra of Phthalocyanine Thin Films: A Valence Band Theoretical Interpretation. Journal of the American Chemical Society, 114, 8669-8675. https://doi.org/10.1021/ja00048a046 
[21] El Damrawi, G., Hassan, A.K. and Shaboub, A. (2018) ${ }^{31} \mathrm{P}$ and ${ }^{27} \mathrm{Al}$ Nuclear Magnetic Resonance Studies on Silver Phosphate Glasses. Magnetic Resonance in Solids, 20, 18202 .

[22] Song, J.L. and Wang, X.J. (2016) Crystal Structure of Mixed-Metal Phosphite, $\mathrm{Pb}_{2} \mathrm{Ga}\left(\mathrm{HP}^{\mathrm{III}} \mathrm{O}_{3}\right)_{3}\left(\mathrm{PVO}_{3}\right)$. Structural Chemistry and Crystallography Communication, 2, 1.

[23] Wu, D.S., Cheng, W.D., Li, X.D., Lan, Y.Z., Chen, D.G., Zhang, Y., Zhang, H. and Gong, Y.J. (2004) First Principles Treatment of Configuration Optimizations, Excited-State Properties, and Dynamic Third-Order Polarizabilities of Chloro-Metal Phthalocyanines $\mathrm{MPcCl}(\mathrm{M}=\mathrm{Al}, \mathrm{Ga}, \mathrm{In})$. The Journal of Physical Chemistry A, 108, 1837-1843. https://doi.org/10.1021/jp0365211

[24] Kadish, K.M., Smith, K.M. and Guilard, R. (2003) The Porphyrin Handbook, Volumes 15-20. Academic Press, San Diego, CA.

[25] Heinemann, S., Heinemann, C., Jäger, M., Neunzehn, J., Wiesmann, H.P. and Hanke, T. (2011) Effect of Silica and Hydroxyapatite Mineralization on the Mechanical Properties and the Biocompatibility of Nanocomposite Collagen Scaffolds. ACS Applied Materials \& Interfaces, 3, 323-4331. https://doi.org/10.1021/am200993q

[26] Miravet, J.F. and Escuder, B. (2005) Reactive Organogels: Self-Assembled Support for Functional Materials. Organic Letters, 7, 4791-4794. https://doi.org/10.1021/ol0514045

[27] Roy, G., Miravet, J.F., Escuder, B., Sanchez, C. and Llusar, M. (2006) Morphology Templating of Nanofibrous Silica through pH-Sensitive Gels: “In Situ” and "Post-Diffusion” Strategies. Journal of Materials Chemistry, 16, 1817-1824. https://doi.org/10.1039/B601561A

[28] Suzuki, M., Nakajima, Y., Sato, T., Shirai, H. and Hanabusa, K. (2006) Fabrication of $\mathrm{TiO}_{2}$ Using L-Lysine-Based Organogelators as Organic Templates: Control of the Nanostructures. Chemical Communications, 20, 377-379.

https://doi.org/10.1039/B510302A 